\title{
The English Film Title Translation Strategies
}

\author{
Xuedong Shi \\ Foreign Language Department, Beijing Information Science \& Technology University, Beijing, China
}

\begin{abstract}
Based on the research of characteristics, functions, translation principles and methods of English film titles, this paper discusses the English film title translation and mainly focus on English film titles domestication and foreignization translation. Good English film should be attractive, attracting the audience to watch the film. A good English film title has a value of artistic, aesthetic and commercial. Cultural translation leads to translators' using domestication, foreignization translation methods in the English film title. Domestication translation and foreignization translation in English film translation is both theoretically and practically.
\end{abstract}

Index Terms - film titles, translation, domestication, foreignization

\section{INTRODUCTION}

In recent years, the domestic cultural market has been prosperous and more and more popular English films have come from European countries and America. Most of those films have been nominated or even been received several honors at many international film awards. The characteristics of English film title are very extraordinary because they are refined and attractive and have capability to generalize the whole content of films to the audience. So this paper will try to analyze the characteristics of English film titles. Film is an art form, which has artistic quality and commercial quality. The English film title translation can influence audience's interest to the film and promote the films' artistic and aesthetic value. Nowadays, English film title translation has some problems. So, translators should find an effective way to solve those problems and discuss this issue.

Language is a unique signal system and the important thing of language system is semanteme which reflects the function of language. Also, English film title is a proper structure, whose feature is the high degree of summarize to the film's theme or content and to arose audience's desire to watch the film. As we all know, the nomination of English film title has both expression and description function. Language has almost six functions, namely, emotive, informative, imperative, aesthetic, phatic and metalinguistic function. (Newmark, 1988) Good translations should reflect three functions as mentioned above.

\section{LITERATURE REVIEW}

English film title translation does not only involve the equivalent function, but also involves the values and principles between target film titles and source film titles. Some translators prefer using domestication and others prefer foreignization translation. Therefore, this part is an attempt to examine strategies that are concerned with the translation of culture: domestication and foreignization. For purposes of contrast, the terms domestication is used here rather than acculturation, for purposes of foreignization. Literal translation and free translation are not same to domestication and foreignization. Domestication and foreignization are two basic translation techniques which guide linguistic and cultural directions of English film title translation. we know that during the opening-up of domestic cultural market and globalization throughout all over the world, the more effective and practical translation theories are domestication and foreignization. But in what way do they reflect film title's characteristics, functions and principles or which techniques or methods? The most important issue we must have a clear mind is how does domestication translation and foreignization work in English film translation. Following contents will give you the details.

Domestication translation and Foreignization translation are the cardinal methods of English film title translation. Domestication translation and Foreignization translation are the terms pointed by Lawrence Venuti. Domestication means use legible and fluent style to let target language readers understand the foreign text, thus readers in the target culture would be familiar with the foreign culture. Foreignization means to take the audience make them feel the distinction both linguistically and culturally. (Nida, 1993)

The famous representative of domestication translation is Eugene Nida. He points out the communicative function of translation. He suggests that the choice of word should adjust so that it can familiarize different kinds of readers. Also, Lawrence Venuti has pointed out foreignization translation, and he is the representative of foreignization translation. Peter Newmark should also be in the school of foreignization; he emphasizes semantic translation that translation version should be faithful to the original one. (Nida, 1993) Nida's Formal and Functional Equivalences mean that formal equivalence focuses on providing some perception in the lexical, grammatical or structure of original text. Functional equivalence is based on the principle of equivalent effect. Venuti's foreignization tactic is to put forward in the cultural background. some translation theorists also point out their ideas in their book, such as Mayoral Asensio, Roberto, Martin, M, .Gottlieb, Henrik, Gambier, Martine, Catford, John C, Bassnett, Susan, Basil, Hatim \& Ian Mason, 
etc. (Nida, 1993)

In China, Liu Yingkai' points out the prevalence of domestication and argues that domestication translation misrepresent the original text. Sun Zhili thinks the main task of translation is to deliver the thought and style of the original text. Xu Jianping suggests that foreignization should be used in English-Chinese translation with domestication as much as possible. Also some theorists in China, for instance, Bao Huinan, Deng Yanchang, Feng Qinghua, Hu Zhuanglin, Jin Di, Qian Yuan, Tan Baoquan,Xie Tianzhen, Xie Jun, Zhang Delu and so on. After the introduction of the studies both abroad and China, the next part would discuss the application of domestication translation and foreignization translation respectively.

Advocators of the domestication strategy base their argument the following reasons: Firstly, $t$ is not only unrealistic but also hazardous to try to force linguistic and cultural norms of the source text into the target text. A good translation should conquer the barriers of languages and cultures. Secondly, since translation is an important and indispensable medium of inter-lingual and intercultural communication, the original culture should be embedded into modes of behavior of the target culture in translation. The translator has the responsibility to prevent cultural conflicts that often cause various kinds of misunderstanding. The translator as the communicator should narrow the cultural gaps to facilitate better understanding. Thus, domestication is not only necessary but also unavoidable. Thirdly, it is impractical and dangerous to exert the source language formula with its culture on the target readers. That means the translator should not presume upon an excessive degree of intellect and imagination on the part of the readers, and force them to understand the source culture beyond the range of knowledge and experiences. So translators must overcome the barrier of the language as well as the culture. And target-language-culture-oriented translation can help readers better understand the source text because the content of the source text is conveyed within the scope of the knowledge of the real world of the readers. It is easier for them to understand the translation if the content and form fall within their ability of comprehension. Lastly, one of the requirements of translation is that language of the translated version is supposed to be natural, idiomatic and intelligible for the target readers in order to avoid misunderstanding caused by the linguistic obstacles that impede it. (Nida, 1993)

Supporters of foreignizing strategy base their arguments on the following facts: Cultural communication and transmittal should be regarded as one of the major aims of translation. The authentic representation of the alien cultural color enables the cultural exchange to be significant and valuable. A translation cannot be considered as faithful if it is incapable of transferring the in the source language exchange and culture. It is by means of foreignizing phenomena translation that cultural can fulfill the duty and responsibility of improving development and prosperity of indigenous cultures. By introducing nutritious heterogeneous cultures and foreign expressions and syntax, the native culture can be enriched a lot. An open and receptive attitude towards foreignness can make the culture of a nation energetic and influential. Translation as an important means of cultural exchange can and should shoulder the responsibility of promoting the cultural prosperity in the nation and even in the whole world. (Bassnett, 1998)

\section{CharaCteristics of ENGLish FiLm Title}

\section{A. Naming Patterns of English Film Title}

a. Named after the character of film

This kind of title accounts for a significant proportion of English film title. For example, Iron Man, in the target film title, it be translated as "gang tie xia". Obviously, both source and target film title are directly reflect the character of the film, so translators can use literal translation in this kind of pattern of English film title directly. Most of the English film titles are made by the name of protagonists and this type of naming pattern can consist of two styles. One is the pure people's name. This character will be mentioned in many times as protagonist or his/her name during the development of the story. In addition, this protagonist will be seen through the whole story. For instance, the English film title "The Hobbit". In this film, Hobbit is the protagonist, and it sets out on an unexpected journey, and its translated version "huo bi te ren" is very suitable.

Another style is the name of the people (animal) with this character's (animal) feature (or relative contents). For example, Edward Scissorhands, the film talking about a story that a "man" who created by human beings who named Edward who has scissors as hands. So, to reflect character's feature, the Chinese translated version is being "jian dao shou ai de hua" to match "scissor hands" in the source English film title. For this type of title's translation, the usual tactic is to add some relative descriptive words with the story, aiming to make more information with the unknown character, and let the character to be more attractive.

Moreover, some titles are made by the names of supporting roles, or even by the name of people who did not appear on the scene. This type of naming pattern reflects a theory that the western culture is always people-centered. Moreover, the represented characters of this kind of film could be historical celebrities, and common people. On this point, it is different from Chinese films. As in many Chinese films, there are rare uses of the name of the character as a film title. Still, the people who been named after the film are basically the historical cultural celebrities.

b. Named after the location, environment or the time of the story's development

This type of title is a memorable production, because all of films' stories of this type of titles are developed in limited circumstances. And the bright spot of this type of tile is that through a small thing it reflects a whole story. Also, the audience would have a general acknowledge of what environment, location that the story has happened. Through those 
elements, audience can estimate what type of the film is. The Terminal, talking about a man trapped in a terminal at an airport when he is denied entry into the United States and at the same time cannot return to his own country, is a good example. All of the things happened are in the "terminal", so when translated as "xing fu zhong dian zhan", the bright spot is through the terminal to reflect a whole story.

c. Named after the development or the motif of the story

Contrasting with former types of film titles, this type of title provides more information and presents general content of the film so that the audience can decide whether to watch those film or not. Many types of this title may exhibit as a style of sentences or the verb phrases, directly describing the plot of the story. E.g. Alice in Wonderland, a 19-year-old Alice returns to the magical world from her childhood adventure, where she gets together with her old friends and learns of her true destiny: to end the Red Queen's reign of threat. According to the pattern of this kind of English title, aiming totally to reflect the motif of the film, the translated film version being "ai li si man you qi jing".

Still, according to the naming patterns of English film title above, translators should follow some translation principles or tactics, such as functional equivalence, information principle, artistic principle, or other tactics, namely, literal translation, free translation, transliteration, etc. What's more, film title translation, according to the theories of domestication and foreignization translation, translators should obey Nida's formal and functional equivalences study, focus attention on the message itself, in both form and content and aiming at being the same as that between the original English film title and the characteristic of the film title. So translators can avoid the misunderstanding of the wrong English film title translation and make clear of the characteristics of English film title itself. All of them would make the translated titles more attractive to the audience.

\section{B. The Function of English Film Title Translation}

a. The informational function

Informational function means through English film title it can deliver the content to audience, and let audience have a better understanding of the film. English film title reflects the film's theme and helps audience to understand the film and acts as straightforward form. For example, The Princess Diaries, just see this title, audience should have an idea that the film is talking about a princess and the things she met. When this title translated as "gong zhu ri ji" would be suitable and reflect the theme directly.

The informational function is the basic function of English film title and it is mainly in its cognitive function and function of commercial advertisement. According to cognitive function, a good English film title should reflect the unique of the film and influence audience's choices. Many English films can be known for much information about the film just through its title, such as protagonist, a place or a location, time, prop, plot or something else. Through the English film title, audience can also know about the type of the film.

b. The advertising function

During the development of English films, it has become an industry. In translation commercial factors must be taken into consideration. At the same time English film title has a commercial value. Except informative form, the title also has a function to lure audience to watch the film. If English film titles can attract audience, then it can create additional market value. So, a unique, unforgettable English film title has a very important significance to a film's commercial value. The translation with suspense and novelty can attract the audience for the first time, and produce their strong desire to watch the film. For instance, Skyfall, as we all know, the series film 007 is famous, and this episode follows the advertising function to meet its commercial factors and lure audience to watch the film. In Chinese, it also uses "007, da po tian ji" to realize this effect. So translators should consider the commercial factor and to realize its commercial value, understand the film's to let an English film title that may be widely accepted and loved by target language audience. If the title is novelty and striking, it can attract a lot of audience.

c. The aesthetic function

English film title is a kind of art; most of them are created from life. So, from the naming of title to the film's content, visual and acoustics are different degrees of art procession. Good English film title has obvious aesthetic quality and can give audience beautiful art enjoyment. The translation of the title of English film need to catch the content of the film in an aesthetic way and the translators should express image, sensibility and language beauty of English film title in their native language and they also should remain beauty in both sound and meaning. Here are the example: Twilight, in Chinese version, it be translated as "mu guang zhi cheng", from this, we can see that translated title is tight in structures and rhythmic in sounds, which can not only express the theme of the film, but also increase the aesthetic effects. Function is a feature of English film title: on the other hand, it leads translators to a right director of English film title translation; moreover, the better theory they can obey is Hans J. Vermeer's study: "aim or purpose" of domestication and foreignization theory which means to produce a text in a target setting for a target purpose. In this way the translated version film title can reflect original film title's function more complete.

\section{Film Title Translation Principles AND Strategies}

\section{A. The Artistic Principle}

The English film title translation emphasizes the deeper grasp of the aesthetic content of the film. Using art style of target language is to convey the original imagine, emotion and art beauty. The English film title tends to pithy and its 
translated film title should be in symmetry, harmony and expressiveness. Just like the translation principle "Elegance", the translation will add humorous language or beautiful and elegant words to the simple phrase, letting film title easy to read. Some Chinese translation theorists have also put forward some points about the artistic principle, such as paying attention to the spirit of English title and keeping the original of the "spirit" and "style" of translation. For example, Waterloo Bridge is the translated in very pithy and sad words to convey the theme of the film-love tragedy.

\section{B. The Cultural Transformation Principle}

IThe translation which has cultural characteristic is one of the most difficult translation context models. The target translation words may express a totally different concept that source language would not have and it would be abstract or specific. (Bassnett, 1998) English film title consists many cultural elements and expresses cultural connotation, such as cultural words or phrases. The cultural transformation principle is not just a process of language transformation, but also a social phenomenon between two culture's communications. For example, this title, Dear John, is a usage means a letter, as to a serviceman, requesting a divorce or ending a personal relationship. To correspond this cultural principle, it should be translated as "fen shou xin".

\section{The Commercial and Entertainment Principle}

English film is an art that combines with cultural and commercial characteristic. So, when translating the English film titles, the translators should pay attention to its commercial element, create titles that audience love to see and hear. The purpose of the commercial English films does not only rely on this art form to fulfill audience's life, but also want make profits. The English film title has its social and commercial benefit. The commercial benefit of society always reflects in the attractive degree to the audience, and influences the box-office directly. For example, The English Patient, telling a story about at the close of World War II, writes a young nurse takes care of a plane crash victim, whose past reveals a love affair. When it translated as "ying lun qing ren", it would reflect the theme of the film and follow it commercial and entrainment principle.

Acting on the principles mentioned above, we can find some translation principles. Literal translation is widely used in English film titles' translation. It remains the content and form of the original as much as possible. It attempts to recreate the precise meaning of the original within the limits of the target language's grammatical structures and to be completely faithful to the intentions of the director. As for English film, literal translation is accessible, if target version corresponds to the original title, then the English film title could use literal translation. It is the most effective method of translation when the source language and target language overlap in function. It is faithful to the original text and proves very simple, practical and feasible; also, the surface structure, the original content and the exotic flavor of the original are retained to a large extent, the audience who like foreign films will be attracted by the foreign elements in the title. Great numbers of English film titles are translated in this way, for example, Snow White and the Seven Dwarfs, almost every audience knows the plot and just translate as "bai xue gong zhu he qi ge xiao ai ren" and that is enough.

Free translation is a strategy that seeks to convey the meaning and the spirit of the original title without sticking to the form mechanically; this method is frequently applied when literal translation is not suitable. Free translation reproduces the matter without keeping the manner, or keeping the content without taking the form of the original. (Newmark, 1988) Free translated version succeeds in exerting the functions of film titles and attracting the audience. It focuses on the target audience and serves the purposes of better communication. Thanks for the distinction between English and Chinese culture, audience have a better understanding of English film's theme, and realize its informative, aesthetic value. In this way free translation is very effective. Free translation consist some techniques, such as addition, omission, and so on. Look at examples: The Bridges of Madison County, this version sounds beautiful and elegant, translated as "lang qiao yi meng" conveying the meaning and the spirit of the original title without sticking to the form mechanically. Based on the original meaning of the title, translators could do some appropriate adjustments to the translation in terms of the film content and style. Sometimes, translators should cast aside unromantic original English film title and use a language style which audience love to see and hear.

Transliteration tries to use a one-to-one correspondence so that an informed reader should be able to reconstruct the original spelling of unknown transliterated words. Transliteration can reserve the sounds of the original to the largest extent, keeping its rhythm and drawing the audience's attention with strong exotic flavor. The main aspects of transliteration are names of people, places, especially, some exotic name, proper noun, historic events. For example, Harry Potter, for a decade, this series film was one of popular film over the world. And harry potter is so familiar to audience from the world. So in China, just translating this kind of film as "ha li bo te" is enough to reserve the sounds of the original to the largest extent, keeping its rhythm and draw the audiences' attention. According to the circumstance, whether keeping the similar original film title will decide to adopt transliteration or free translation or not. Then try transliteration and add some suitable words to express the theme of the English film title. Translators can add some further information about the film to express the complete meaning and also attract the audience, especially the films named after person's names, places and things. Moreover, meeting audience acceptance and cultural expectations of the target language in the form and content is another method. For Shrek, using transliteration as "shi lai ke" is good and pluses free translation as "guai wu" can reflect its figure "monster" and add some further information about the film to express the complete meaning when they are translated literally and also attract the audience. There are some other translation variations: increase or decrease on the number of words. The aim is to let the original English film title be 
accustomed to the target English film title so that audience can have better understanding of the film, such as, Life of Pie.

\section{CONCLUSION}

At present, foreignization translation strategies in the translation of film titles occupy the position of the mainstream. But in the film title translation, foreignization translation and domestication are meant to coexist in a very long period of time. Foreignization has been regarded as positive qualities although the translation standard is keep changing. Anyway, the research of English film title translation should combine with the reality. To have fantabulous English film translation, translators should know the characteristics of English film titles. English film title translation has to consider many factors, such as the content of film, the psychology of target audience, and so on. Good English film translation should be pithy, attracting. It should obey functional equivalence, information principle, artistic principle, or some tactics, literal translation, free translation, transliteration and so on. It also uses some basic methods: literal translation, free translation, transliteration.

Moreover, foreignization translation is based on those primary methods, the advantages of foreignization is that it would be more practical combing with English film title's commercial and aesthetic effects. Besides it is more appropriate to different English film title translation and translators do a better job when translating English film titles following the method. During the use of foreignization translation, audience has began to accept the foreignization translation strategy for its' convenience of audience's understanding. At the same time it caters the taste of audience and reflects culture of source film title's countries. The use of foreignization translation will increase of commercial value and enhance the cultural exchange between the nations. In short, the use of foreignization depends on the need of translation practice. Under foreignization translation strategy, the English film title translation's works would be more felicitous and they can reflect the values of English film titles though the domestication method will still be coexistent.

\section{REFERENCES}

[1] Alexander,L.G. (2002). New Concept English. Peking: Foreign Language Teaching and Research Press.

[2] Bassnett, Susan. (1998).Translation Studies (Revised Edition). Shanghai: Shanghai Foreign Language Education Press.

[3] Chen, T.Y. (1989). Translation Techniques from English to Chinese. Peking: Foreign Language Teaching and Research Press.

[4] Deng, Y.C. (1992). Language and Culture. Peking: Foreign Language Teaching and Research Press.

[5] Fan, J.C. (1992). The Appreciation of English Rhetoric. Shanghai: Shanghai Jiaotong University Press.

[6] Feng, C.H. (1998). Practical Translation Course. Shanghai: Shanghai Foreign Language Education Press.

[7] Guo,Z.Z. (1988). Translation between English and Chinese Practical Course. Wuchang: Wuhan University Press.

[8] Hatim, Basil and Mason, Ian. (1990). Discourse and the Translator. London: Longman Group UK Limited.

[9] He,S. (2003). English and Chinese Language Contrast Research. Shanghai: Shanghai Foreign Language Education Press.

[10] Jack C. Richards, John Platt and Heidi Platt. (2000). Longman Dictionary of Language Teaching \& Applied Linguistics. London: Longman Group, England

[11] Lawrence Venuti. (1995). The Translator's Invisibility -- A History of Translation. Shanghai: Shanghai Foreign Language Education Press.

[12] Lefevere, Andre. (1992). Traslation, History and Culture - A Sourcebook. London and New York: Routeledge.

[13] Newmark, P. (1988).Textbook of Translation. London: Prentice Hall.

[14] Newmark, P. (2002). Approaches to Translation. Shanghai: Shanghai Foreign Language Education Press.

[15] Nida, Eugene A. (1993). Language, Culture, and Translating, Shanghai: Shanghai Foreign Language Education Press.

[16] Nida, Eugene A. (2001). Language and Culture. Shanghai: Shanghai Foreign Language Education Press.

[17] Nida, Eugene A. (1964). Toward a Science of Translating. New York: Brill Academic Publishers

[18] Nida, E. A. \& Taber, C. (2004). The Theory and Practice of Translation. Shanghai: Shanghai Foreign Language Education Press.

[19] Rojer T. Bell. (1991). Translation and Translating: Theory and Practice. London and New York: Longman

[20] Samovar, L.A \& Porter. (2000). Communication between Cultures. Peking: Foreign Language Teaching and Research Press.

[21] Shan, Q.C. (2002). Chinese English Translation Techniques. Peking: Foreign Language Teaching and Research Press.

[22] Snell-Hornby, Mary. (2001). Translation Studies: An Integrated Approach. Shanghai: Foreign Education Press.

[23] Schaffner, Christian, and Kelley-Holmes, Helen. Ed. (1995). Cultural Functions of Translation. London: Multilingual Matters Ltd.

[24] Toury, Gideon. (2001). Descriptive Translation Studies And Beyond. Shanghai: Shanghai Foreign Language Education Press.

[25] Tytler, A. (1791). Essays on the Principles of Translation. London: Dent.

[26] Wilss, Wolfram. (1982).The Science of Translation. Shanghai: Shanghai Foreign Language Education Press.

[27] Zheng, Y.L. (1994). English-Chinese Dictionary. Beijing: The Commercial Press.

Xuedong Shi was born in Huhhot, Inner Mongolia, China in 1974. He received his MA degree in translation in Middlesex University, Britain, in 2004. He is currently a lecturer in the Foreign Language Department, Beijing Information Science University, Beijing, China. His academic research mainly focuses on translation and applied linguistics. 